\title{
PENGARUH CURRENT RATIO, WORKING CAPITAL TURNOVER, DEBT TO EQUITY RATIO, DAN TOTAL ASSETS TURNOVER TERHADAP RETURN ON INVESTMENT PADA PERUSAHAAN MAKANAN DAN MINUMAN YANG TERDAFTAR DI BURSA EFEK INDONESIA
}

\author{
Christina, Monica, Agnes Aurelia, Sherley Fitria, Lina, Maya Sabirina Panggabean \\ Program Studi Akuntansi, Universitas Prima Indonesia, Jalan Belanga No.1 Simp.Ayahanda Medan, Sumatera \\ Utara, 20118, Indonesia \\ E-mail: christinatan3008@gmail.com
}

\begin{abstract}
The purpose of this research is to provide and increase knowledge for the readers and to analyze the effect of Current Ratio, Working Capital Turnover, Debt to Equity Ratio, and Total Assets Turnover on Return on Investment in food and beverage companies listed on the Indonesia Stock Exchange for the period 2012-2017. The study population used was 20, the research sample of 11 companies. The research method uses quantitative statistics. The data analysis technique uses the classic assumption test. Hypothesis testing is assessed by multiple linear regression test, $T$ test, and $F$ test. The hypothesis test results of the determination coefficient obtained Adjusted R Square (R2) value of 58\%, so it can be said that the variable Current Ratio (X1), Debt to Equity Ratio (X2), Working Capital Turnover (X3), and Total Assets Turnover (X4) affect the Return on Investment (Y) of 58\% and the remaining $42 \%$ is influenced by other variables that are not found in this study.

Keywords: Current Ratio; Working Capital Turnover; Debt to Equity Ratio; Total Assets Turnover; Return on Investment
\end{abstract}

\section{PENDAHULUAN}

Tiap perusahaan memiliki tujuan utama yaitu untuk memaksimumkan nilai perusahaannya dalam memperoleh keuntungan jangka panjang. Perusahaan yang ingin tumbuh lebih maju daripada perusahaan lain tentunya harus merumuskan strategi yang tajam dalam dunia bisnis. Untuk itu perusahaan membutuhkan modal yang memadai agar dapat membiayai kegiatan operasionalnya. Usaha peningkatan modal dapat dilakukan salah satunya dengan cara menarik dana dari luar yaitu melalui pasar modal. Melalui pasar modal, pembentukan modal dan akumulasi dana diarahkan untuk meningkatkan partisipasi masyarakat. Hal ini bukan hanya sebagai wadah sumber pembiayaan, tetapi juga sebagai sumber investasi. Agar dapat memenuhi tujuan perusahaan secara maksimal, maka keuntungan yang diperoleh perusahaan harus lebih tinggi dari kegiatan operasionalnya sehingga para investor berminat untuk melakukan penanaman modal pada perusahaan tersebut.

Di Indonesia sendiri perusahaan barang konsumsi makanan dan minuman berkembang pesat, dikarenakan produk yang dihasilkan oleh perusahaan ini merupakan kebutuhan primer masyarakat pada umumnya. Perusahaan ini sangat diperlukan sehingga peluangnya cenderung menguntungkan baik di masa kini maupun di masa yang akan datang. Hal ini dapat diamati dari jumlah perusahaan pada Bursa Efek Indonesia semakin banyak. Alasan peneliti memilih sektor industri makanan dan minuman karena saham-sahamnya yang paling stabil dengan krisis ekonomi dibandingkan sektor lain sebab barang konsumsi tetap dibutuhkan setiap saat untuk kelangsungan hidup masyarakat. Adapun masalah yang ditemukan dalam penelitian ini tidak terlepas dari seberapa besar perusahaan dapat memenuhi kebutuhan pendanaan atau modal perusahaan serta pengendalian aktiva lancar agar 
menghasilkan laba maksimum. Dalam 20 populasi, terdapat 2 perusahaan yang mengalami penurunan laba secara berturut-turut, yaitu PT Tri Banyan Tirta Tbk (ALTO) mengalami kerugian pada tahun 2014-2017 dan Prasidha Aneka Niaga Tbk (PSDN) mengalami kerugian pada tahun 2014-2016 secara berturut-turut. Hal ini mungkin dikarenakan adanya penurunan harga pasaran global untuk komoditas bisnis utama dan perusahaan lebih mengutamakan komoditas lain sehingga hal ini akan berdampak terhadap penurunan kinerja operasional emiten.

Penanggulangan yang dapat dilakukan oleh perusahaan agar dapat mencapai keuntungan kembali adalah dengan memperhatikan beberapa aspek penting seperti melakukan peningkatan penjualan dan memperkecil nominal hutang. Kemampuan perusahaan untuk menghasilkan laba merupakan penentu utama agar dapat meyakinkan para investor untuk berinvestasi di perusahaan tersebut. Dalam mempertahankan laba, perusahaan harus menggunakan sumber daya secara efisien dan mengendalikan hutang agar dapat mengoptimalkan kegiatan perusahaan dalam menciptakan tingkat penjualan yang tinggi.

Beberapa penelitian yang mengkaji variabel yang sama dalam penelitian ini terhadap profitabilitas (ROI), seperti peneliti Adlirahman dan Muhammad (2015) dalam penelitiannya yang berjudul "Pengaruh Likuiditas, Efisiensi Modal Kerja dan Investasi Aktiva Tetap Terhadap Profitabilitas". Hasil dari penelitian ini menjelaskan bahwa Rasio Lancar mempunyai pengaruh signifikan terhadap Return on Investment. Tetapi hasil penelitian ini berbeda dari hasil penelitian Hermansyah (2017) yang berjudul "Pengaruh Kondisi Modal Kerja Terhadap Profitabilitas". Hasil dari penelitian ini memaparkan bahwa Rasio Lancar tidak memiliki pengaruh signifikan terhadap Return on Investment.

Peneliti Pujiati dan Widya (2015) dalam penelitiannya yang berjudul "Pengaruh Penggunaan Modal Kerja Terhadap Tingkat Profitabilitas". Hasil penelitian tersebut menjelaskan bahwa Perputaran Modal Kerja mempunyai pengaruh yang signifikan terhadap Return on Investment. Namun hasil penelitian ini berbeda dengan peneliti Ananda (2017) dalam penelitiannya yang berjudul "Pengaruh Perputaran Modal Kerja dan Perputaran Piutang Terhadap Profitabilitas". Hasil dari penelitian ini memaparkan bahwa Perputaran Modal Kerja tidak mempunyai pengaruh yang signifikan terhadap Return on Investment.

Peneliti Rusnaeni (2018) dalam penelitiannya yang berjudul "Pengaruh Current Ratio dan Debt to Equity Ratio Terhadap Return on Investment pada PT. Bhuwanatala Indah Permai, Tbk Periode 2007 - 2015". Hasil penelitian ini memaparkan bahwa Debt to Equity Ratio mempunyai pengaruh signifikan terhadap Return on Investment. Namun hasil penelitian ini berbeda dari hasil penelitian Sarikadarwati, S.E., M.Si Ak. dan Rizza Yansari (2016) yang berjudul "Pengaruh Current Ratio dan Debt to Equity Ratio Terhadap Return on Invesment". Hasil penelitian ini menjelaskan Debt to Equity Ratio tidak mempunyai pengaruh signifikan terhadap Return on Investment.

Peneliti Al-Faruqy (2016) dalam penelitiannya yang berjudul "Pengaruh Current Ratio, Debt to Equity Ratio dan Total Asset Turn Over Terhadap Return on Investment (Studi Pada Perusahaan Sektor Manufaktur Yang Terdaftar Di JII Tahun 2011- 2014)”. Hasil penelitian ini memaparkan bahwa Total Asset Turn Over mempunyai pengaruh signifikan terhadap Return on Investment. Namun hasil penelitian ini berbeda dari hasil penelitian Valentina (2016) yang berjudul "Pengaruh Working Capital Turnover dan Total Assets Turnover Terhadap Return on Invesment Pada PT AKR Corporindo, Tbk. dan Entitas Anak". Hasil penelitian ini menjelaskan Total Asset Turn Over tidak mempunyai pengaruh signifikan terhadap Return on Investment. 


\section{TINJAUAN PUSTAKA}

\subsection{Current Ratio Terhadap Return on Investment}

Supardi, dkk. (2016) menjelaskan Current Ratio adalah kemampuan suatu perusahaan untuk memenuhi kebutuhan utang ketika jatuh tempo. Semakin tinggi Current Ratio berarti semakin besar kemampuan perusahaan untuk memenuhi kewajiban jangka pendek. Current Ratio yang terlalu tinggi menunjukkan kelebihan aktiva lancar yang menganggur. Jadi hal tersebut tidak baik bagi profitabilitas perusahaan karena aktiva lancar menghasilkan return yang lebih rendah dibandingkan dengan aktiva tetap.

Wartono (2018) menjelaskan bahwa likuiditas perusahaan merupakan pertimbangan dalam menentukan kebijakan dividen. Karena dividen bagi perusahaan merupakan kas keluar, maka semakin besar posisi kas dan likuiditas perusahaan secara keseluruhan akan semakin besar pula kemampuan perusahaan untuk membayar dividen.

Mashady, dkk. (2014) menjelaskan bahwa bagi pihak kreditur, perusahaan yang ingin memaksimalkan profitabilitas untuk meningkatkan laba perusahaan akan dipandang baik. Karena perusahaan memiliki peluang yang besar untuk membayar kewajiban tepat pada waktunya. Adapun hipotesis yang dapat diajukan sebagai berikut :

$\mathbf{H}_{1}$. Current Ratio secara parsial berpengaruh terhadap Return on Investment

2.2 Working Capital Turnover Terhadap Return on Investment

Yuliani, dkk. (2015) mengemukakan bahwa rasio perputaran modal kerja yang tinggi membuktikan bahwa modal kerja perusahaan digunakan secara baik dan tepat sesuai dengan kebutuhan dan kondisi perusahaan. Peningkatan penjualan otomatis akan meningkatkan profit yang akan didapatkan oleh perusahaan.

Desliana dan Adi (2018) mengemukakan bahwa penggunaan modal kerja secara efisien mengindikasikan pengelolaan modal kerja yang baik yang tampak dari perputaran modal kerjanya. Semakin pendek periode perputaran modal kerjanya, maka semakin cepat perputaran modal kerja perusahaan dan akan membuat perusahan semakin baik dalam menggunakan modal kerjanya.

Fung (2016) menjelaskan bahwa dalam kegiatan operasional perusahaan, untuk tujuan pencapaian yang tinggi dan meningkatkan laba, diperlukan modal kerja. Perputaran modal kerja membandingkan penjualan yang telah dicapai dengan modal kerja bersih yang dimiliki perusahaan. Semakin tinggi perputaran modal kerja, maka semakin efektif dan efisien pengelolaan modal kerja tersebut. Adapun hipotesis yang dapat diajukan sebagai berikut :

H2. Working Capital Turnover secara parsial berpengaruh terhadap Return on Investment

\subsection{Debt to Equity Ratio Terhadap Return on Investment}

Rusnaeni (2018) mengutarakan bahwa Debt to Equity ratio atau rasio utang modal ini menggambarkan sejauh mana modal pemilik dapat menutupi hutang- hutang kepada pihak luar. Rasio ini semakin bagus jika semakin rendah. Apabila total modal lebih tinggi dari total hutang atau minimal sama, hal ini aman bagi pihak luar.

Susanto (2017) menjelaskan bahwa Debt to Equity Ratio merupakan indikator dari rasio solvabilitas yang dimana merupakan rasio mengukur sampai sejauh mana aktiva perusahaan dibiayai dengan utang. Rasio ini merupakan perbandingan antara Total Debt dengan Total Equity. Debt to Equity Ratio yang semakin rendah semakin baik karena aman bagi kreditor saat likuidasi.

Sarikadarwati dan Rizza (2016) mengutarakan bahwa Debt to Equity Ratio menunjukan nilai relatif antara total utang dengan total equitas. Semakin besar Debt to Equity Ratio menunjukan bahwa struktur modal lebih banyak memanfaatkan kewajiban dibandingkan dengan ekuitas, sehingga berdampak semakin besar beban perusahaan terhadap pihak luar (kreditur). Bagi perusahaan semakin besar rasio ini akan semakin menguntungkan, tetapi bagi pihak bank makin besar rasio ini berarti akan semakin besar resiko yang 
ditanggung atas kegagalan perusahaan yang mungkin terjadi. Adapun hipotesis yang dapat diajukan sebagai berikut :

H3. Debt to Equity Ratio secara parsial berpengaruh terhadap Return on Investment

2.4 Total Assets Turnover Terhadap Return on Investment

Menurut Asmirantho dan Resta (2016) semakin efektif perusahaan menggunakan asetnya, semakin sedikit aset yang diperlukan. Dan ini penting karena dapat terlihat bagaimana pengelolaan yang dilakukan manajemen perusahaan dalam penggunaan aktiva di dalam perusahaan. Total Asset Turnover berperan penting bagi pemilik dan manajemen perusahaan, karena Total Asset Turnover menunjukkan apakah seluruh aktiva yang ada di perusahaan digunakan secara efisien atau tidak. Angka Assets Turnover yang tinggi merupakan indikasi bahwa manajemen perusahaan telah mengelola harta perusahaan dengan baik.

Sari, dkk. (2015) menguraikan Total aktiva (Total Asset Turnover) merupakan kecepatan berputarnya aktiva usaha dalam suatu periode tertentu yang diperoleh dengan membandingkan penjualan dengan total aktiva. Jika perputaran aktiva naik, maka profitabilitas akan meningkat.

Al-Faruqy (2016) memberikan kesimpulan bahwa Total Asset Turnover berpengaruh positif terhadap Return on Investment. Kenaikan atau penurunan nilai Total Asset Turnover akan sangat berdampak pada kenaikan atau penurunan laba perusahaan. Nilai Total Asset Turnover yang semakin tinggi akan memberikan kontribusi terhadap Return on Investment yang semakin tinggi atau sebaliknya nilai Total Asset Turnover yang semakin rendah akan memberikan dampak terhadap nilai Return on Investment. Adapun hipotesis yang dapat diajukan sebagai berikut :

H. Total Assets Turnover secara parsial berpengaruh terhadap Return on Investment

\section{METODE PENELITIAN}

\subsection{Pendekatan Penelitian}

Metode pendekatan penelitian yang dipakai pada riset ini sebagai berikut, yaitu metode penelitian kuantitatif. Sugiyono (2012:13), menjabarkan penelitian kuantitatif dikatakan menjadi metode penelitian sebagai landasan filsafat positivisme, dipakai bagi pendiagnosis atas populasi atau sampel tertentu, teknik pengutipan sampel biasanya dilakukan dengan cara acak, pengambilan data memanfaatkan instrumen penelitian, studi data bersifat kuantitas/statistik sebagai alat untuk mengevaluasi hipotesis yang sudah pernah dipraktekkan.

\subsection{Jenis dan Sifat Penelitian}

Jenis penelitian yang dipakai yaitu penelitian deskriptif sebagai sistem penelitian yang digunakan saat menyusun suatu bayangan yang terorganisasi akan penjelasan objektif yang bermula pada pokok atau bahan penelitian. Penelitian deskriptif berpusat dalam pemaparan terstruktur mengenai kebenaran yang didapat pada saat penelitian dilaksanakan (Sanusi, 2012 : 13). Sifat penelitian ini yaitu penelitian kausalitas, yang menakar kemampuan ikatan antara 2 variabel atau lebih, juga memperlihatkan arah hubungan antara variabel bebas dan variabel terikat.

\subsection{Populasi dan Sampel}

Populasi riset ini yaitu 20 perusahaan makanan dan minuman yang tertera pada Bursa Efek Indonesia periode 2012 - 2017. Teknik sampling yang dipakai pada penelitian ini adalah purposive sampling dengan kriteria yaitu :

1. Perusahaan yang termuat dalam sub-sektor makanan dan minuman di Bursa Efek Indonesia periode 2012-2017. 
2. Perusahaan makanan dan minuman secara berturut-turut menyuguhkan dan mempublikasikan laporan keuangan yang telah diaudit di Bursa Efek Indonesia periode 2012-2017.

3. Perusahaan makanan dan minuman yang menyimpan profit positif di Bursa Efek Indonesia periode 2012-2017.

Total jumlah data sampel yang dipakai dalam penelitian ini yaitu 66 sampel yang diambil dari jumlah sampel perusahaan 11 dikalikan dengan 6 tahun penelitian.

\subsection{Teknik Pengumpulan Data}

Data yang dipakai adalah data sekunder dengan teknik pengumpulan data yang digunakan dalam riset ini adalah kepustakaan dan dokumentasi dengan pengumpulkan data sekunder yang diperlukan berbentuk laporan keuangan perusahaan makanan dan minuman yang tercantum di Bursa Efek Indonesia periode 2012-2017.

\subsection{Definisi Operasional}

a. $\quad$ Current Ratio $\left(\mathrm{X}_{1}\right)$

Current Ratio ialah rasio yang membandingkan antara aktiva lancar yang dimiliki oleh perusahaan dengan hutang jangka pendek (Mashady, 2014). Mengenai indikator yang dipakai yaitu sebagai berikut :

\section{b. $\quad$ Working Capital Turnover $\left(\mathrm{X}_{2}\right)$}

$$
\text { Current Ratio }=\frac{\text { Aktiva Lancar }}{\text { Utang Lancar }}
$$

Perputaran Modal Kerja ialah rasio yang menunjukkan banyaknya penjualan yang dapat diperoleh perusahaan untuk tiap rupiah modal kerja (Mashady, 2014) dengan indikator sebagai berikut :

c. $\quad$ Debt to Equity Ratio $\left(\mathrm{X}_{3}\right)$

$$
\text { Perputaran Modal Kerja }=\frac{\text { Penjualan }}{\text { Modal Kerja Bersih }}
$$

Debt to Equity Ratio ialah rasio yang sering digunakan sebagai alat untuk menilai hutang terhadap ekuitas (Wartono, 2018). Adapun indikator yang digunakan sebagai berikut :

d. Total Assets Turnover $\left(\mathrm{X}_{4}\right)$

$$
\text { Debt to Equity Ratio }=\frac{\text { Total Hutang }}{\text { Modal }}
$$

Total Asset Turnover ialah rasio yang digunakan untuk mengukur perputaran semua aktiva yang dimiliki perusahaan (Chairul dan Yunita, 2017). Adapun indikator yang digunakan sebagai berikut :

e. $\quad$ Return on Investment $(\mathrm{Y})$

$$
\text { Total Asset Turnover }=\frac{\text { Penjualan }}{\text { Total Asset }}
$$

Return on Investment ialah kemampuan perusahaan menghasilkan laba dari aktiva yang dipergunakan (Mashady, 2014). Adapun indicator yang digunakan sebagai berikut:

\subsection{Uji Asumsi Klasik}

$$
\text { Return On Investment }=\frac{\text { Laba Bersih }}{\text { Total Asset }}
$$

a. Uji Normalitas

Uji normalitas untuk menakar apakah dalam model regresi, variabel penggangu atau residual mempunyai distribusi normal menurut Ghozali (2013: 160). Seperti diketahui bahwa uji $\mathrm{t}$ dan $\mathrm{F}$ mengasumsikan bahwa nilai residual menyusuri distribusi normal. Uji statistik menjadi tidak valid untuk total sampel kecil jika asumsi ini tidak ditaati.

b. Uji Autokorelasi

Ghozali (2013 : 110) menguraikan, uji autokorelasi ialah pengujian apakah dalam model regresi linear ada koneksi antara kesalahan pengganggu pada periode $\mathrm{t}$ dengan 
kesalahan pengganggu pada periode t-1 sebelumnya. Jikalau terjadi korelasi, maka disebutkan ada problem autokorelasi. Autokorelasi muncul karena observasi yang bersambungan sepanjang waktu berkaitan satu sama lainnya.

c. Uji Multikolonieritas

Ghozali (2013: 105) menguraikan, Uji multikolonieritas merupakan percobaan apakah model regresi ditemukan adanya koneksi antar variabel bebas (independen). Model regresi yang berfaedah sewajarnya tidak terjadi korelasi di antara variabel independen. Apabila variabel independen saling berkorelasi, alhasil variabel-variabel ini tidak ortogonal. Variabel ortogonal merupakan variabel independen yang nilai korelasi antar sesama variabel independen sama dengan nol.

d. Uji Heteroskedastisitas

Ghozali (2013: 139) menjelaskan, Uji heteroskedastisitas bertujuan menyelidiki apakah dalam model regresi terjadi ketidaksamaan variansi dari residual satu pemantauan ke pemantauan yang lain. Jika variance dari residual satu pengamatan ke pengamatan lain tetap, sehingga disebut homoskedastisitas dan jikalau berbeda disebut heteroskedastisitas.

\subsection{Model Penelitian}

Pengujian hipotesis yang digunakan dalam penelitian adalah dengan menggunakan analisis regresi linier berganda. Model regresi yang digunakan adalah sebagai berikut :

$$
\begin{aligned}
& \mathrm{Y}=\mathrm{a}+\mathrm{b} 1 \mathrm{X} 1+\mathrm{b} 2 \mathrm{X} 2+\mathrm{b} 3 \mathrm{X} 3+\mathrm{b} 4 \mathrm{X} 4+\ldots+\mathrm{bnXn} \\
& \text { Keterangan }: \\
& \mathrm{Y} \quad=\text { Variabel terikat (dependen) } \\
& \mathrm{X}(1,2,3, \ldots)=\text { Variabel bebas (independen) } \\
& \mathrm{a} \quad=\text { Konstanta } \\
& \mathrm{b}(1,2,3, \ldots)=\text { Nilai koefisien regresi }
\end{aligned}
$$

\subsection{Pengujian Hipotesis Secara Parsial $(t)$}

Uji signifikansi koefisien regresi secara parsial $(t)$ menurut Sanusi (2011:138): "Uji signifikansi terhadap masing-masing koefisien regresi diperlukan untuk mengetahui signifikan tidaknya pengaruh dari masing-masing variabel bebas (Xi) terhadap variabel terikat (Y)".

\subsection{Pengujian Hipotesis Secara Simultan $(F)$}

Uji seluruh koefisien regresi secara serempak dapat dilakukan dengan menggunakan uji $F$ yang dimana menurut Sanusi (2011: 137): "Nilai yang digunakan untuk melakukan uji serempak adalah nilai $F$ hitung. Uji $F$ yang signifikan menunjukkan bahwa variasi variabel terikat dijelaskan sekian persen oleh variabel bebas secara bersama-sama adalah benar-benar

\begin{tabular}{|c|c|c|c|c|c|}
\hline & $\mathbf{N}$ & Minimum & Maximum & Mean & Std. Deviation \\
\hline CR & 66 & 0.51 & 8.63 & 2.2156 & 1.57611 \\
\hline WCTO & 66 & -881.39 & 75.95 & -7.5835 & 113.57183 \\
\hline DER & 66 & 0.17 & 3.03 & 0.9671 & 0.53846 \\
\hline TATO & 66 & 0.55 & 3.06 & 1.4127 & 0.60768 \\
\hline ROI & 66 & 0.01 & 0.66 & 0.1282 & 0.12150 \\
\hline Valid N (listwise) & 66 & & & & \\
\hline
\end{tabular}
nyata dan bukan terjadi karena kebetulan".

\section{HASIL PENELITIAN DAN PEMBAHASAN}

\subsection{Hasil Penelitian}

\subsubsection{Statistik Deskriptif}

Tabel 1. Hasil Statistik Deskriptif 
Tabel diatas menunjukkan nilai minimum, nilai maksimum, nilai rata-rata (mean), dan standar deviasi dari variabel Current Ratio, Working Capital Turnover, Debt To Equity Ratio, Total Assets Turnover dan Return on Investment dengan uraian :

a. Variabel Current Ratio memiliki jumlah sampel sebanyak 66, dengan nilai minimum 0,51 adalah PT Multi Bintang Indonesia Tbk pada tahun 2014 dan nilai maksimum 8,63 adalah PT Delta Djakarta Tbk pada tahun 2017 sedangkan nilai rata-rata (mean) 2.2156 dengan standar deviasi 1.57611 .

b. Variabel Working Capital Turnover memiliki jumlah sampel sebanyak 66, dengan nilai minimum -881.39 adalah PT Siantar Top Tbk pada tahun 2012 dan nilai maksimum 75.95 adalah PT Wilmar Cahaya Indonesia Tbk pada tahun 2015 sedangkan nilai rata-rata (mean) -7.5835 dengan standar deviasi 113.57183.

c. Variabel Debt to Equity Ratio memiliki jumlah sampel sebanyak 66, dengan nilai minimum 0,17 adalah PT Delta Djakarta Tbk pada tahun 2017 dan nilai maksimum 3.03 adalah PT Multi Bintang Indonesia Tbk pada tahun 2014 sedangkan nilai ratarata (mean) 0.9671 dengan standar deviasi 0.53846 .

d. Variabel Total Assets Turnover memiliki jumlah sampel sebanyak 66, dengan nilai minimum 0,55 adalah PT Nippon Indosari Corpindo Tbk pada tahun 2017 dan nilai maksimum 3.06 adalah PT Wilmar Cahaya Indonesia Tbk pada tahun 2017 sedangkan nilai rata-rata (mean) 1.4127 dengan standar deviasi 0.60768 .

e. $\quad$ Variabel Return on Investment memiliki jumlah sampel sebanyak 66, dengan nilai mininum 0,01 adalah PT Sekar Bumi Tbk pada tahun 2017 dan nilai maksimum 0,66 adalah PT Multi Bintang Indonesia Tbk pada tahun 2013 sedangkan nilai rata-rata (mean) 0,1282 standar deviasi 0,12150.

\subsubsection{Uji Normalitas}

Uji normalitas dipakai sebagai suatu data dalam model regresi, residual (variabel penganggu) mempunyai distribusi normal.

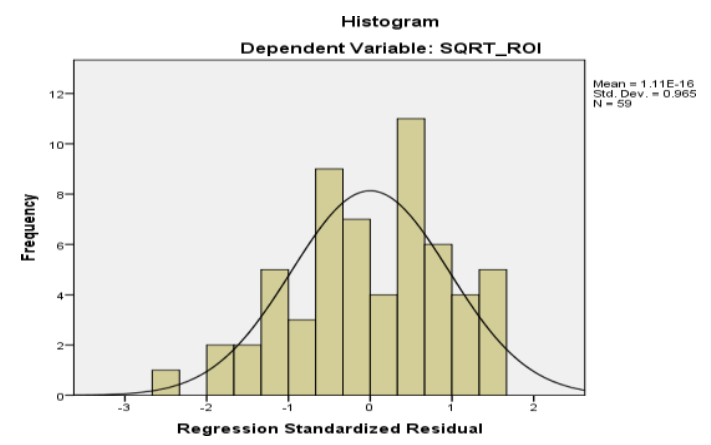

Gambar 1. Grafik Histogram

Diagram histogram diatas membuktikan kurva cenderung simetris (U) dan membuktikan hasil asumsi klasik tidak menimbulkan masalah pada uji normalitas sebab data berasumsi normal maka terhindar dari normalitas. 


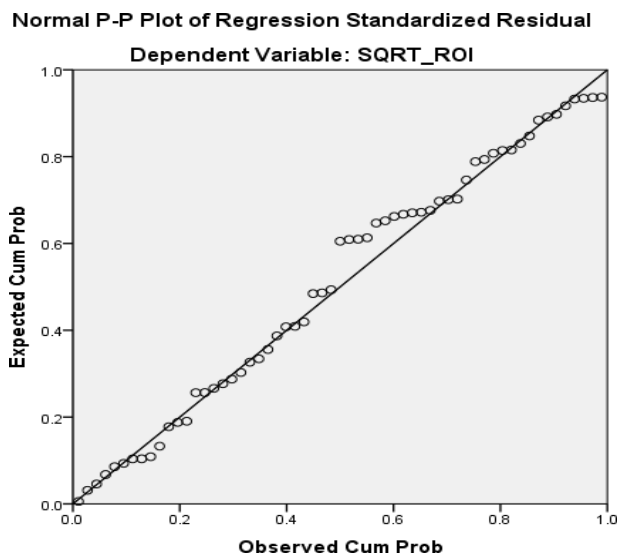

Gambar 2. Grafik P-Plot

Grafik ini menggambarkan titik-titik yang tersebar mendekati garis diagonal. Selain digunakan analisis grafik, kita juga perlu analisis statistik untuk memastikan apakah data tersebut berdistribusi normal.

Tabel 2. One-Sample Kolmogorov-Smirnov Test

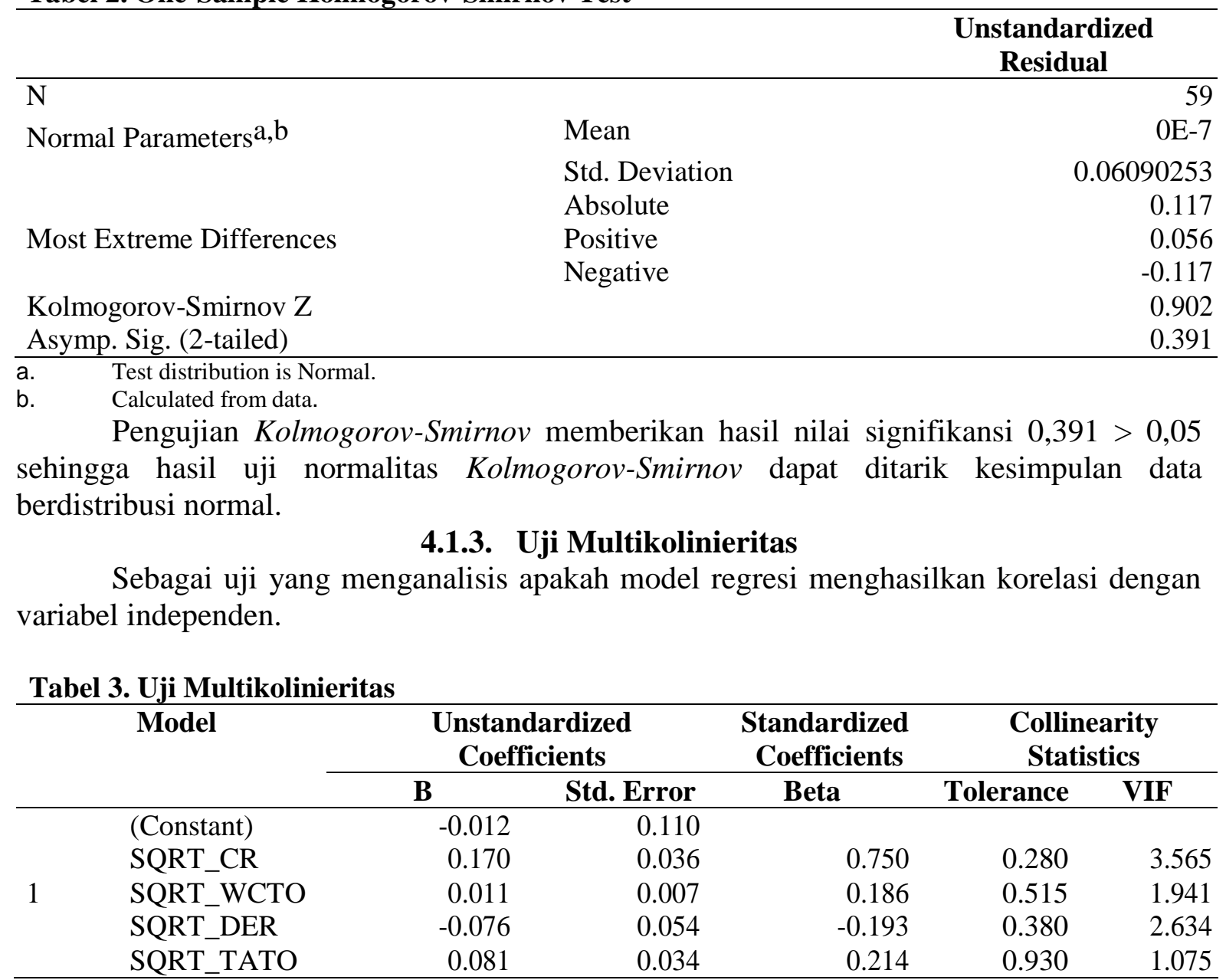

a. Dependent Variable: SQRT_ROI

Nilai tolerance variabel CR $(0,280)$, WCTO $(0,515)$, DER $(0,380)$, dan TATO $(0,930)$ lebih besar dari 0,1. Nilai VIF CR $(3,565)$, WCTO $(1,941)$, DER $(2,634)$, dan TATO $(1,075)$ lebih kecil dari 10 sehingga tidak terjadi multikolinieritas. 


\subsubsection{Uji Autokorelasi}

Agar memberikan kepastian yang lebih akurat kita menggunakan autokorelasi biasa disebut uji Durbin-Watson.

Tabel 4. Uji Autokorelasi

\begin{tabular}{lccccr}
\hline Model & R & R Square & $\begin{array}{c}\text { Adjusted R } \\
\text { Square }\end{array}$ & $\begin{array}{c}\text { Std. Error of the } \\
\text { Estimate }\end{array}$ & Durbin-Watson \\
\hline 1 & $0.781^{\mathrm{a}}$ & 0.609 & 0.580 & 0.06312 & 1.868 \\
\hline a. & $\begin{array}{l}\text { Predictors: (Constant), SQRT_TATO, SQRT_DER, SQRT_WCTO, SQRT_CR } \\
\text { b. }\end{array}$ & Dependent Variable: SQRT_ROI & & &
\end{tabular}

Berdasarkan uji tabel autokolerasi di atas, dapat dilihat bahwa nilai dw sebesar 1.868, dengan melihat tabel uji dw dengan tingkat signifikan 5\% untuk jumlah variable bebas $=4$ dan jumlah sampel $=66$ diperoleh nilai du sebesar 1,7319 dan dl sebesar 1,4758, sehingga dapat disimpulkan bahwa data terbebas dari masalah uji autokorelasi karena $\mathrm{du}<\mathrm{dw}<4$-du / $1.7319<1.868<2.2681$.

\subsubsection{Uji Heteroskedastisitas}

Suatu model regresi yang baik adalah tidak terjadi heterokedastisitas. Ada beberapa cara untuk menguji ada tidaknya situasi heterokedastisitas dalam varian error terms untuk model regresi.

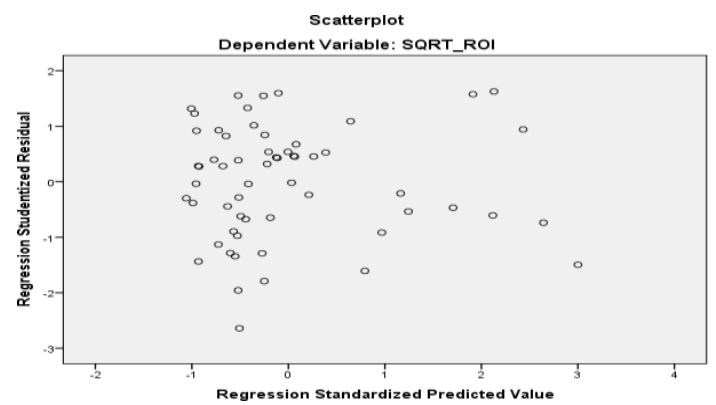

Gambar 4. Grafik Scatterplot

Gambar diatas bahwa data tersebar tidak membentuk suatu pola tertentu dan secara acak. Data tersebar diatas dan dibawah garis 0 yang menunjukkan tidak terjadi adanya heteroskedastisitas. Pengujian ada tidaknya heteroskedastisitas dapat menggunakan metode lain, yaitu Metode Park Test seperti dibawah ini:

Tabel 5. Uji Park

\begin{tabular}{rlrrrr}
\hline \multirow{2}{*}{ Model } & \multicolumn{2}{c}{ Unstandardized Coefficients } & \multicolumn{2}{c}{$\begin{array}{c}\text { Standardized } \\
\text { Coefficients }\end{array}$} & Sig. \\
\cline { 3 - 5 } & & \multicolumn{3}{c}{ Beta } & \\
\hline \multirow{2}{*}{1} & (Constant) & -7.659 & 3.187 & & 0.020 \\
& SQRT_CR & -0.022 & 1.055 & -0.005 & 0.983 \\
& SQRT_WCTO & 0.257 & 0.209 & 0.218 & 0.224 \\
& SQRT_DER & -2.005 & 1.581 & -0.262 & 0.210 \\
& SQRT_TATO & 1.897 & 0.976 & 0.257 & 0.057 \\
\hline
\end{tabular}

a. Dependent Variable: SQRT_UjiPark

Pengujian Park diatas memperlihatkan nilai signifikansi Current Ratio $(0,983)$, Debt to Equity Ratio (0,210), Working Capital Turnover (0,224) dan Total Assets Turnover (0.057) $>0,05$ sehingga kesimpulannya tidak terjadi heteroskedastisitas. 


\subsubsection{Hasil Analisis Data Penelitian}

Pengujian hipotesis yang digunakan dalam penelitian adalah dengan menggunakan analisis regresi linier berganda. Model regresi yang digunakan adalah sebagai berikut :

Tabel 6. Persamaan Regresi

\begin{tabular}{|c|c|c|c|c|}
\hline \multicolumn{2}{|c|}{ Model } & \multicolumn{2}{|c|}{ Unstandardized Coefficients } & \multirow{2}{*}{$\begin{array}{c}\begin{array}{c}\text { Standardized } \\
\text { Coefficients }\end{array} \\
\text { Beta }\end{array}$} \\
\hline & & $\mathbf{B}$ & Std. Error & \\
\hline \multirow{5}{*}{1} & (Constant) & -0.012 & 0.110 & \\
\hline & SQRT_CR & 0.170 & 0.036 & 0.750 \\
\hline & SQRT_WCTO & 0.011 & 0.007 & 0.186 \\
\hline & SQRT_DER & -0.076 & 0.054 & -0.193 \\
\hline & SQRT_TATO & 0.081 & 0.034 & 0.214 \\
\hline
\end{tabular}

a. Dependent Variable: SQRT_ROI

$$
\begin{aligned}
\text { SQRT_ROI }= & -0,012+0,170 \text { SQRT_CR }+0,011 \text { SQRT_WCTO }-0,076 \text { SQRT_DER } \\
& +0,081 \text { SQRT_TATO }
\end{aligned}
$$

Makna dari persamaan regresi linear diatas adalah :

a. Nilai konstanta sebesar -0,012 artinya jika variabel Current Ratio $\left(\mathrm{X}_{1}\right)$, Working Capital Turnover $\left(\mathrm{X}_{2}\right)$, Debt to Equity Ratio $\left(\mathrm{X}_{3}\right)$, dan Total Assets Turnover $\left(\mathrm{X}_{4}\right)$, dianggap nol atau tidak ada, maka Return on Investment $(\mathrm{Y})$ adalah sebesar -0,012 kali.

b. Nilai koefisien Current Ratio ( $\left.\mathrm{X}_{1}\right)$ sebesar 0,170 dan bertanda positif. Ini menunjukkan bahwa setiap peningkatan Current Ratio $\left(\mathrm{X}_{1}\right)$ satu kali maka Return on Investment $(\mathrm{Y})$ akan mengalami peningkatan sebesar 0,170 kali.

c. $\quad$ Nilai koefisien Working Capital Turnover $\left(\mathrm{X}_{2}\right)$ sebesar 0,011 dan bertanda positif. Ini menunjukkan bahwa setiap peningkatan Working Capital Turnover $\left(\mathrm{X}_{2}\right)$ satu kali maka Return on Investment (Y) akan mengalami peningkatan sebesar 0,011 kali.

d. Nilai koefisien Debt to Equity Ratio $\left(\mathrm{X}_{3}\right)$ sebesar -0,076 dan bertanda negatif. Ini menunjukkan bahwa setiap peningkatan debt to equity ratio $\left(\mathrm{X}_{3}\right)$ satu kali maka Return on Investment (Y) akan mengalami penurunan sebesar -0,076 kali.

e. $\quad$ Nilai koefisien Total Assets Turnover $\left(\mathrm{X}_{4}\right)$ sebesar 0,081 dan bertanda positif. Ini menunjukkan bahwa setiap peningkatan Total Assets Turnover $\left(\mathrm{X}_{4}\right)$ satu kali maka Return on Investment (Y) akan mengalami peningkatan sebesar 0,081 kali.

\subsubsection{Koefisien Determinasi}

Koefisien determinasi ditujukan untuk mengetahui seberapa besar kemampuan model dalam menerangkan variabel terikat.

Tabel 7. Koefisien Determinasi

\begin{tabular}{lcccc}
\hline \multicolumn{1}{c}{ Model } & R & R Square & $\begin{array}{c}\text { Adjusted R } \\
\text { Square }\end{array}$ & $\begin{array}{c}\text { Std. Error of the } \\
\text { Estimate }\end{array}$ \\
\hline 1 & $0.781^{\mathrm{a}}$ & 0.609 & 0.580 & 0.06312 \\
\hline $\begin{array}{l}\text { a. Predictors: (Constant), SQRT_TATO, SQRT_DER, SQRT_WCTO, SQRT_CR } \\
\text { b. Dependent Variable: SQRT_ROI }\end{array}$ & & &
\end{tabular}

Hasil uji koefisien determinasi diperoleh nilai Adjusted $R$ Square $\left(\mathrm{R}^{2}\right)$ koefisien determinasi sebesar 0,580 atau sebesar 58\% maka dapat dikatakan variabel Current Ratio $\left(\mathrm{X}_{1}\right)$, Debt to Equity Ratio $\left(\mathrm{X}_{2}\right)$, Working Capital Turnover $\left(\mathrm{X}_{3}\right)$ dan Total Assets Turnover $\left(\mathrm{X}_{4}\right)$ berpengaruh terhadap Return on Investment (Y) sebesar $58 \%$ dan sisanya sebesar $42 \%$ dipengaruhi oleh variabel lain yang tidak kedapatan dalam penelitian ini. 


\subsubsection{Pengujian Hipotesis Secara Simultan (Uji F)}

Uji $F$ digunakan untuk menguji apakah variabel independen secara bersama-sama mempengaruhi variabel dependen.

Tabel 8. Uji Statistik F

\begin{tabular}{llrrrrc}
\hline & Model & Sum of Squares & df & Mean Square & F & Sig. \\
\hline & Regression & 0.336 & 4 & 0.084 & 21.057 & $0.000^{\mathrm{b}}$ \\
1 & Residual & 0.215 & 54 & 0.004 & & \\
& Total & 0.551 & 58 & & & \\
\hline a. & Dependent Variable: SQRT_ROI & & & \\
b. & Predictors: (Constant), SQRT_TATO, SQRT_DER, SQRT_WCTO, SQRT_CR & &
\end{tabular}

Uji signifikan simultan menghasilkan $\mathrm{F}_{\text {hitung }}$ sebesar 21.057 (F) dengan nilai signifikan 0,000 (Sig.), sedangkan $F_{\text {tabel }}$ adalah sebesar 2.52 dengan signifikan 0,05. Dengan demikian maka kesimpulannya adalah $\mathrm{F}_{\text {hitung }}>\mathrm{F}_{\text {tabel }}$ yaitu $21.057>2.52$. Maka keputusannya adalah $\mathrm{H}_{0}$ ditolak dan $\mathrm{H}_{1}$ diterima, artinya variabel jadi Current Ratio $\left(\mathrm{X}_{1}\right)$, Debt to Equity Ratio $\left(\mathrm{X}_{2}\right)$, Working Capital Turnover $\left(\mathrm{X}_{3}\right)$ dan Total Assets Turnover $\left(\mathrm{X}_{4}\right)$ secara simultan berpengaruh signifikan terhadap Return on Investment $(\mathrm{Y})$ pada perusahaan makanan dan minuman yang terdaftar pada Bursa Efek Indonesia tahun 2012-2017.

\subsubsection{Pengujian Hipotesis Secara Parsial (Uji t)}

Uji t digunakan untuk menguji apakah variabel independen secara individual mempengaruhi variabel dependen.

Tabel 9. Uji Statistik t

\begin{tabular}{|c|c|c|c|c|c|c|}
\hline \multirow{2}{*}{\multicolumn{2}{|c|}{ Model }} & \multicolumn{2}{|c|}{$\begin{array}{c}\text { Unstandardized } \\
\text { Coefficients }\end{array}$} & \multirow{2}{*}{$\begin{array}{c}\begin{array}{c}\text { Standardized } \\
\text { Coefficients }\end{array} \\
\text { Beta }\end{array}$} & \multirow[t]{2}{*}{$\mathbf{t}$} & \multirow[t]{2}{*}{ Sig. } \\
\hline & & B & Std. Error & & & \\
\hline \multirow{5}{*}{1} & (Constant) & -0.012 & 0.110 & & -0.111 & 0.912 \\
\hline & SQRT_CR & 0.170 & 0.036 & 0.750 & 4.671 & 0.000 \\
\hline & SQRT_WCTO & 0.011 & 0.007 & 0.186 & 1.567 & 0.123 \\
\hline & SQRT_DER & -0.076 & 0.054 & -0.193 & -1.400 & 0.167 \\
\hline & SQRT_TATO & 0.081 & 0.034 & 0.214 & 2.423 & 0.019 \\
\hline
\end{tabular}

Dengan demikian hasil dari uji t dapat dijelaskan sebagai berikut :

a. Variabel Current Ratio $\left(\mathrm{X}_{1}\right)$ mempunyai nilai thitung 4.671 dengan nilai signifikan 0.000 sedangkan $t_{\text {tabel }}$ adalah sebesar 1.99962 dengan signifikan 0,05. Dengan demikian maka kesimpulannya adalah $t_{\text {hitung }}>t_{\text {tabel }}$ yaitu $4.671>1.99962$. Maka keputusannya adalah $\mathrm{H}_{0}$ ditolak dan $\mathrm{H}_{1}$ diterima, artinya variabel Current Ratio secara parsial berpengaruh signifikan terhadap Return on Investment pada perusahaan makanan dan minuman yang terdaftar pada Bursa Efek Indonesia tahun 2012-2017.

b. Variabel Working Capital Turnover $\left(\mathrm{X}_{2}\right)$ mempunyai nilai thitung 1.567 dengan nilai signifikan 0.123 sedangkan $t_{\text {tabel }}$ adalah sebesar 1.99962 dengan signifikan 0,05 . Dengan demikian maka kesimpulannya adalah $t_{\text {hitung }}<t_{\text {tabel }}$ yaitu $1.567<1.99962$. Maka keputusannya adalah $\mathrm{H}_{0}$ ditolak dan $\mathrm{H}_{1}$ diterima, artinya variabel Working Capital Turnover secara parsial tidak berpengaruh signifikan terhadap Return on Investment pada perusahaan makanan dan minuman yang terdaftar pada Bursa Efek Indonesia tahun 2012-2017.

c. Variabel Debt to Equity Ratio ( $\left.\mathrm{X}_{3}\right)$ mempunyai nilai thitung -1.400 dengan nilai signifikan 0.167 sedangkan tabel adalah sebesar 1.99962 dengan signifikan 0,05. Dengan demikian maka kesimpulannya adalah $\mathrm{t}_{\text {hitung }}<\mathrm{t}_{\text {tabelyaitu }}-1.400<1.99962$. 
Maka keputusannya adalah $\mathrm{H}_{0}$ ditolak dan $\mathrm{H}_{1}$ diterima, artinya variable Debt to Equity Ratio secara parsial tidak berpengaruh signifikan terhadap Return on Investment pada perusahaan makanan dan minuman yang terdaftar pada Bursa Efek Indonesia tahun 2012-2017.

d. Variabel Total Assets Turnover $\left(\mathrm{X}_{4}\right)$ mempunyai nilai $t_{\text {hitung }} 2.423$ dengan nilai signifikan 0.019 sedangkan tabel adalah sebesar 1.99962 dengan signifikan 0,05. Dengan demikian maka kesimpulannya adalah $t_{\text {hitung }}>t_{\text {tabelyaitu }} 2.423>1.99962$. Maka keputusannya adalah $\mathrm{H}_{0}$ ditolak dan $\mathrm{H}_{1}$ diterima, artinya variabel Total Assets Turnover secara parsial berpengaruh signifikan terhadap Return on Investment pada perusahaan makanan dan minuman yang terdaftar pada Bursa Efek Indonesia tahun 2012-2017.

\subsection{Pembahasan}

\subsubsection{Pengaruh Current Ratio terhadap Return on Investment}

Berdasarkan hasil penelitian bahwa Current Ratio secara parsial berpengaruh signifikan terhadap Return on Investment pada perusahaan makanan dan minuman yang terdaftar pada Bursa Efek Indonesia tahun 2012-2017. Hasil ini menjelaskan Current Ratio yang tinggi akan terjadi peningkatan laba yang bersangkutan. Current Ratio yang tinggi dapat menunjukkan adanya kas berlebih sehingga dapat digunakan untuk melakukan pembayaran terhadap hutang yang belum dilunasi. Hasil penelitian ini sesuai dengan teori Mashady,dkk (2014) yang menyatakan bahwa bagi pihak kreditur, perusahaan yang ingin memaksimalkan profitabilitas untuk meningkatkan laba perusahaan akan dipandang baik. Karena perusahaan memiliki peluang yang besar untuk membayar kewajiban tepat pada waktunya. Akan tetapi penelitian ini tidak sesuai dengan penelitian Rusnaeni (2018) menyatakan bahwa variabel Current Ratio tidak berpengaruh signifikan terhadap Return on Investment.

\subsubsection{Pengaruh Working Capital Turnover terhadap Return on Investment}

Berdasarkan hasil penelitian bahwa Working Capital Turnover secara parsial tidak berpengaruh signifikan terhadap Return on Investment pada perusahaan makanan dan minuman yang terdaftar pada Bursa Efek Indonesia tahun 2012-2017. Hal ini menerangkan bahwa perputaran dana yang diinvestasikan dari kas tidak dapat kembali cepat. Rasio perputaran modal kerja yang rendah apabila berhubungan pada keuntungan berarti untuk mencapai penjualan tertentu perusahaan mampu mengelola modal kerja dengan efisien. Pengembangan penjualan bersamaan dengan peningkatan keuntungan yang dicapai emiten. Hasil penelitian ini sesuai dengan teori Desliana dan Adi (2018) bahwa penggunaan modal kerja secara efisien mengindikasikan pengelolaan modal kerja yang baik yang tampak dari perputaran modal kerjanya. Semakin pendek periode perputaran modal kerjanya, maka semakin cepat perputaran modal kerja perusahaan dan akan membuat perusahan semakin baik dalam menggunakan modal kerjanya. Tetapi penelitian ini tidak sejalan dengan Mashady,dkk (2014) yang menyatakan bahwa secara parsial Working Capital Turnover berpengaruh signifikan terhadap Return on Investment.

\subsubsection{Pengaruh Debt to Equity Ratio terhadap Return on Investment}

Berdasarkan hasil penelitian bahwa Debt to Equity Ratio secara parsial tidak berpengaruh signifikan terhadap Return on Investment pada perusahaan makanan dan minuman yang terdaftar pada Bursa Efek Indonesia tahun 2012-2017. Hasil penelitian ini menyatakan bahwa perubahan Debt to Equity Ratio yang biasanya diperoleh dari laporan keuangan berpengaruh tidak signifikan pada laba perusahaan manufaktur yang terdaftar di Bursa Efek Indonesia. Hal ini mungkin menyebabkan para investor dalam melakukan transaksi seperti pengunaan hutang atau pengembalian bunga pada akhirnya akan mempengaruhi keuntungan di masa mendatang. Hasil penelitian ini 
tidak sesuai dengan teori Rusnaeni (2018) mengutarakan bahwa Debt to Equity Ratio atau rasio utang modal ini menggambarkan sejauh mana modal pemilik dapat menutupi hutang-hutang kepada pihak luar. Rasio ini semakin bagus jika semakin rendah. Apabila total modal lebih tinggi dari total hutang atau minimal sama, hal ini aman bagi pihak luar. Akan tetapi hasil penelitian ini sejalan dengan penelitian Fung (2016) yang menyatakan bahwa Debt to Equity Ratio tidak berpengaruh terhadap Return on Investment.

\subsubsection{Pengaruh Total Assets Turnover terhadap Return on Investment}

Berdasarkan hasil penelitian bahwa Total Assets Turnover secara parsial berpengaruh signifikan terhadap Return on Investment pada perusahaan makanan dan minuman yang terdaftar pada Bursa Efek Indonesia tahun 2012-2017. Penelitian ini memliki perubahan nilai Total Asset Turnover sehingga memberikan kontribusi yang positif dan signifikan terhadap Return on Investment perusahaan manufaktur yang tercatat di Bursa Efek Indonesia ialah kenaikan atau penurunan nilai Total Asset Turnover akan mengalami kenaikan atau penurunan keuntungan perusahaan, nilai Total Asset Turnover yang semakin tinggi akan memberikan kontribusi terhadap Return on Investment yang semakin tinggi atau sebaliknya. Hasil penelitian ini sesuai dengan teori Sari,dkk (2015) menguraikan Total Aktiva (Total Assets Turnover) merupakan kecepatan berputarnya aktiva usaha dalam suatu periode tertentu yang diperoleh dengan membandingkan penjualan dengan total aktiva. Jika perputaran aktiva naik, maka profitabilitas akan meningkat. Akan tetapi penelitian ini tidak sesuai dengan penelitian Valentina (2016) menyatakan bahwa Total Assets Turnover tidak berpengaruh terhadap Return on Investment.

\section{e. KESIMPULAN DAN SARAN}

\subsection{Kesimpulan}

Kesimpulan dari hasil penelitian ini adalah :

a. $\quad$ Current Ratio secara parsial berpengaruh signifikan terhadap Return on Investment pada perusahaan makanan dan minuman yang terdaftar pada Bursa Efek Indonesia tahun 2012-2017.

b. Working Capital Turnover secara parsial tidak berpengaruh signifikan terhadap Return on Investment pada perusahaan makanan dan minuman yang terdaftar pada Bursa Efek Indonesia tahun 2012-2017.

c. Debt to Equity Ratio secara parsial tidak berpengaruh signifikan terhadap Return on Investment pada perusahaan makanan dan minuman yang terdaftar pada Bursa Efek Indonesia tahun 2012-2017.

d. Total Assets Turnover secara parsial berpengaruh signifikan terhadap Return on Investment pada perusahaan makanan dan minuman yang terdaftar pada Bursa Efek Indonesia tahun 2012-2017.

e. Current Ratio, Working Capital Turnover, Debt to Equity Ratio, Total Assets Turnover berpengaruh terhadap Return on Investment dengan hasil koefisien determinasi sebesar 58\% dan sisanya sebesar $42 \%$ dipengaruhi oleh variabel lain yang tidak dijelaskan dalam penelitian ini.

\subsection{Saran}

Saran dari hasil penelitian ini adalah :

a. Berdasarkan hasil penelitian, disarankan kepada perusahaan makanan dan minuman yang terdaftar di Bursa Efek Indonesia untuk lebih memperhatikan Current Ratio dan Total Assets Turnover yang diterapkan karena secara parsial kedua variabel tersebut dapat mempengaruhi Return on Investment perusahaan. 
b. Bagi peneliti selanjutnya yang ingin melanjutkan penelitian ini, disarankan untuk meneliti atau menambah variabel yang diteliti oleh peneliti seperti likuiditas, good corporate governance, dan lainnya.

\section{DAFTAR PUSTAKA}

Adlirahman, S., \& Nazar, M. R. (2015). Pengaruh Likuiditas, Efisiensi Modal Kerja Dan Investasi Aktiva Tetap Terhadap Profitabilitas (studi Kasus Pada Perusahaan Telekomunikasi Yang Terdaftar Di Bursa Efek Indonesia (BEI) Periode 20092014). eProceedings of Management, 2(3).

Al-Faruqy, A. F. (2016). Pengaruh Current Ratio, Debt To Equity Ratio Dan Total Asset Turn Over Terhadap Return On Investment (Studi pada perusahaan sektor manufaktur yang terdaftar di JII tahun 2011-2014). SCIENTICA, 3(1).

Ananda, A. N., \& Ibrahim, M. (2017). Pengaruh Perputaran Modal Kerja Dan Perputaran Piutang Terhadap Profitabilitas Pada Perusahaan Pertambangan Sub Sektor Minyak Dan Gas Bumi Listing Di Bei. Jurnal Online Mahasiswa Fakultas Ilmu Sosial dan Ilmu Politik Universitas Riau, 4(2), 1-14.

Asmirantho, E., \& Rosdiana, R. (2018). Influence Against Receivable Management Capabilities In Producing Income On The Basic Industry And Chemical Company Sub Sector Feed Listed In Indonesia Stock Exchange. JIMFE (Jurnal Ilmiah Manajemen Fakultas Ekonomi), 2(1), 53-66.

Chairul, D. N. D., \& Yunita, I. (2017). Analisis Pengaruh Net Profit Margin (NPM), Total Asset Turnover (TATO), Current Ratio (CR), Dan Net Income (NI) Terhadap Return On Investment (ROI) (pada Perusahaan Sektor Transportasi Di Bursa Efek Indonesia Tahun 2013-2015). eProceedings of Management, 4(3).

Desliana, E., \& Irawan, A. (2018). Pengaruh Perputaran Modal Kerja dan Perputaran Persediaan Terhadap Profitabilitas Perusahaan Property dan Real Estate yang Terdaftar di Bursa Efek Indonesia Periode 2009-2013. Journal of Applied Managerial Accounting, 2(1), 47-50.

Fung, N. S. (2016). Pengaruh Working Capital Turnover, Debt Ratio Dan Total Assets Turnover Terhadap Return On Investment Pada Subsektor Otomotif Dan Komponen Yang Terdaftar Di Bursa Efek Indonesia. FIN-ACC (Finance Accounting), 1(5).

Ghozali, I. (2013). Aplikasi Analisis Multivariate dengan Program IBM SPSS 21 Update $\boldsymbol{P L S}$. Edisi Ketujuh. Semarang: Universitas Diponegoro.

Hermansyah, H. (2017). Pengaruh Kondisi Modal Kerja Terhadap Profitabilitas (Studi Empiris: Pada Perusahaan Manufaktur Yang Terdaftar pada BEI Katagori Saham LQ 45 Periode 2007 Sampai Dengan 2011). Transparansi Jurnal Ilmiah Ilmu Administrasi, 9(2), 244-254.

Mashady, D. (2014). Pengaruh Working Capital Turnover (WCT), Current Ratio (CR), Dan Debt to Total Assets (DTA) Terhadap Return on Investment (ROI) (Studi Pada Perusahaan Farmasi Yang Terdaftar Di Bursa Efek Indonesia Tahun 20092012). Jurnal Administrasi Bisnis, 7(1).

Pujiati, L., \& Ratna, W. (2015). Pengaruh Penggunaan Modal Kerja Terhadap Tingkat Profitabilitas Pada Perusahaan Sub Sektor Kosmetik Dan Keperluan Rumah Tangga Yang Terdaftar Di Bursa Efek Indonesia. Eksis: Jurnal Riset Ekonomi dan Bisnis, 10(2).

Rusnaeni, N. (2018). Pengaruh Current Ratio Dan Debt To Equity Ratio Terhadap Return On Investment Pada Pt. Bhuwanatala Indah Permai, Tbk Periode 2007-2015. Jurnal Semarak, 1(2). 
Sanusi, A. (2011). Metodologi Penelitian Bisnis. Jakarta: Salemba Empat.

Sanusi, A. (2012). Metodologi Penelitian Akuntansi. Jakarta: Salemba Empat.

Sari, B., Listianingsih, E., \& Wuryanti, L. (2015). Pengaruh Perputaran Kas, Perputaran Piutang, Perputaran Persediaan Dan Perputaran Total Aktiva Terhadap Profitabilitas Pada Perusahaan Manufaktur Sektor Industri Dasar Dan Kimia Yang Terdaftar Dibursa Efek Indonesia (BEI) Periode 2009-2013. Jurnal Riset Akuntansi dan Manajemen Malahayati, 4(2).

Sarikadarwati, S. E., Ak, M. S., Yansari, R., \& Sriwijaya, J. A. P. N. Pengaruh Current Ratio Dan Debt To Equity Ratio Terhadap Return On Invesment Pada Perusahaan Asuransi Yang Terdaftar Dibursa Efek Indoonesia (Bei) Tahun 2009-2012. Jurnal Akuntanika, 2(2).

Sugiyono. 2012. Metode Penelitian Bisnis. Cetakan Keenam Belas. Bandung: Alfabeta.

Supardi, H., Suratno, H. S. H., \& Suyanto, S. (2018). Pengaruh Current Ratio, Debt to Asset Ratio, Total Asset Turnover dan Inflasi Terhadap Return on Asset. JIAFE (Jurnal Ilmiah Akuntansi Fakultas Ekonomi), 2(2), 16-27.

Susanto, K. B. (2017). Pengaruh Current Ratio Dan Total Debt To Equity Ratio Terhadap Return On Investment (Roi) Pada Sub Sektor Properti Dan Real Estate Yang Terdaftar Di Bursa Efek Indonesia. BIS-MA (Bisnis Manajemen), 1(9).

Valentina, H. (2016). Pengaruh Working Capital Turnover Dan Total Assets Turnover Terhadap Return On Investment Pada Pt Akr Corporindo, Tbk. Dan Entitas Anak. BIS-MA (Bisnis Manajemen), 1(5).

Wartono, T. (2018). Pengaruh Current Ratio (CR) Dan Debt To Equity Ratio (DER) Terhadap Return On Asset (ROA) (Studi Pada Pt Astra International, Tbk). KREATIF: Jurnal Ilmiah Prodi Manajemen Universitas Pamulang, 6(2), 78-97.

Yuliani, E. P. (2015). Pengaruh Perputaran Modal Kerja (WCTO), Perputaran Aset Tetap (FATO), dan Debt To Total Assets (DTA) terhadap Return On Investment (ROI) (Studi pada Perusahaan Multinasional Sektor Manufaktur yang Terdaftar di Bei Periode 2011-2014). Jurnal Administrasi Bisnis, 26(2). 